\title{
A Study of Perinatal Outcome in Women with Preterm Labour at a Tertiary Care Hospital
}

\author{
Dr. Kavita Chaudhary ${ }^{1}$, Dr. Nupur Hooja ${ }^{2}$, Dr. Premlata Mital $^{3 *}$, Dr. Urmila Kumari ${ }^{4}$, Dr. Saloni Sethi ${ }^{5}$, Dr. Ankita \\ Chaudhary ${ }^{6}$ \\ ${ }^{1}$ PG Student, ${ }^{2,3}$ Senior Professor, ${ }^{4,5,6}$ PG Student, Department of Obstetrics and Gynaecology S.M.S. Medical College, Jaipur 302004 Rajasthan, India
}

*Corresponding author: Dr. Premlata Mital

\section{Abstract}

Introduction: Preterm labor is the leading cause of neonatal morbidity all over the world. Over the past two decades despite major preventive efforts, the incidence of preterm birth has remained constant at about $5-10 \%$ of live births. The etiology is often multifactorial and poorly understood. Neonatal complications which arise from preterm births are birth asphyxia, respiratory distress, low birth weight, infective neonatal hypoglycemia and neonatal death. With this background the present study was done to find out perinatal outcome in women presenting with preterm labour. Material and methods: The present study was a descriptive study conducted in the Department of Obstetrics and Gynaecology. 100 consecutive women presented with preterm labour between 28 to $<37$ weeks were included in the study after obtaining written informed consent. Mode of delivery and neonatal outcome were noted. Data were compiled and analyzed. Results: Majority of the women were between 20 to 35 years of age, Hindu, Literate, belonging to rural area, low socio-economic status, and had normal BMI. $60 \%$ women were primigravida. $65 \%$ women had gestational age $\geq 34$ weeks. Mean weight of the babies in our study was $1.7 \pm 0.4 \mathrm{Kg}$ and mean APGAR score at 5 min was $7.02 \pm 1.03$. $46 \%$ babies were admitted in NICU for various reasons and $12 \%$ babies had perinatal death. Most common reason for NICU admission was birth asphyxia (42\%) followed by extreme prematurity (16\%), septicemia (12\%) and jaundice (11\%). Conclusion: Appropriate and innovative preventive intervention, customized individuals need may prevent preterm births and improve neonatal outcomes.

Keywords: Preterm birth, neonatal outcome, perinatal morbidity, perinatal mortality.

Copyright @ 2020: This is an open-access article distributed under the terms of the Creative Commons Attribution license which permits unrestricted use, distribution, and reproduction in any medium for non-commercial use (NonCommercial, or CC-BY-NC) provided the original author and source are credited.

\section{INTRODUCTION}

Preterm birth is still one of the biggest problems in obstetrics all over the world. Preterm birth is defined by WHO as any birth after the gestation of viability (20-28 weeks, depending on definition) and before 37 completed weeks of gestation or fewer than 259 days since the last day of menstrual period [1]. $60 \%$ of preterm birth occurs in developing countries such as Africa and South Asia and rest of the world contributes to $40 \%$ of preterm, hence having an impact globally [1]. Preterm labor is the leading cause of neonatal morbidity in developed as well as developing countries.

Over the past two decades despite major preventive efforts, the incidence of preterm birth has remained constant at about $5-10 \%$ of live births in developed and more in developing countries [2, 3]. It is estimated that 50 to $60 \%$ of preterm births occur following spontaneous labor, $30 \%$ due to PROM and rest are iatrogenic termination for maternal or fetal benefit [4-6]. Though perinatal mortality in the UK has been fallen by two thirds over the last 30 years, the fall has been due to improved survival of preterm infants largely brought about by advance in neonatal care, but the incidence of preterm labour has not fallen significantly [7].

The etiology is often multifactorial and poorly understood. Contributory features include hormonal changes, uterine overdistension, cervical disease, infection/inflammation, uteroplacental ischemia/ hemorrhage, or immunologic pathology [8, 9]. Various predisposing factors for preterm birth include 
increasing age, illiteracy, poverty and people living in the rural areas [10]. Neonatal complications which arise from preterm births are birth asphyxia, respiratory distress, low birth weight, infective neonatal hypoglycemia and neonatal death [11]. With this background the present study was done to find out perinatal outcome in women presenting with preterm labour.

\section{MATERIAL AND METHODS}

The present study was a prospective descriptive study conducted in the Department of Obstetrics and Gynaecology, S.M.S. Medical College Jaipur, Rajasthan over a period of 6 months from June 2019 onward. 100 consecutive women presented with preterm labour between 28 to $<37$ weeks were included in the study after obtaining written informed consent. Women with premature rupture of membrane, any associated medical disorders, congenital malformation of the foetus and intrauterine foetal death were excluded from the study. After examination of the women on admission they were managed and monitored and mode of delivery and neonatal outcome in terms of gender, APGAR at 5 minutes, birth weight, need for NICU admission, and perinatal death were noted. Data were compiled and statistically analyzed.

\section{RESULTS}

Socio-demographic profile of the women presented with preterm labour is shown in table 1 . Majority of the women (85\%) were between 20 to 35 years of age with mean age $23.5 \pm 3.9$ years. Maximum number of women were Hindu (89\%), Literate (57\%), belonging to rural area $(54 \%)$, low socio-economic status (46\%) and admitted as unbooked cases (53\%). Majority of the women had their weight between $45-$ $60 \mathrm{Kg}(52 \%)$, height between $155-170 \mathrm{~cm}(49 \%)$ and normal BMI (73\%). Mean weight, height and BMI were $58.3 \pm 9.8 \mathrm{Kg}, 156.2 \pm 5.9 \mathrm{~cm}$ and $23.9 \pm 3.5 \mathrm{Kg} / \mathrm{m}^{2}$ respectively.

Table 2 shows obstetric profile of the women. Majority of the women were primigravida (60\%). $63 \%$ women were nulliparous. Mean gravidity and parity was $1.5 \pm 0.7$ and $1.3 \pm 0.5$ respectively. Past history of preterm delivery and abortion was present in $5 \%$ and $4 \%$ women respectively and $3 \%$ women had previous cesarean delivery. $65 \%$ women had gestational age 34 weeks or above. $77 \%$ women had none or inadequate ANC visit before admitting to the hospital. $96 \%$ women delivered vaginally.
Neonatal outcome is shown in table 3. $41 \%$ neonates were male and $59 \%$ were female. $72 \%$ babies had birth weight $1.5 \mathrm{Kg}$ or more. Mean weight of the babies in our study was $1.7 \pm 0.4 \mathrm{Kg}$. $58 \%$ babies had APGAR score 7 or more at 5 minute. The mean APGAR score at $5 \mathrm{~min}$ in our study was $7.02 \pm 1.03$. $46 \%$ babies were admitted in NICU for various reasons and $12 \%$ babies had perinatal death.

Table 4 shows various reasons for NICU admission. Most common indication was birth asphyxia $(42 \%)$ followed by extreme prematurity (16\%), septicemia $(12 \%)$ and jaundice $(11 \%)$.

Table-1: Socio-demographic profile of the women presented with preterm labour

\begin{tabular}{|c|c|c|}
\hline Variables & Number & Percentage \\
\hline \multicolumn{3}{|l|}{ Age } \\
\hline$<20$ & 9 & 9 \\
\hline $20-35$ & 85 & 85 \\
\hline$>35$ & 6 & 6 \\
\hline \multicolumn{3}{|l|}{ Religion } \\
\hline Hindu & 89 & 89 \\
\hline Muslim & 11 & 11 \\
\hline \multicolumn{3}{|l|}{ Residence } \\
\hline Urban & 46 & 46 \\
\hline Rural & 54 & 54 \\
\hline \multicolumn{3}{|c|}{ Literacy status } \\
\hline Literate & 57 & 57 \\
\hline Illiterate & 43 & 43 \\
\hline \multicolumn{3}{|c|}{ Socio-economic status } \\
\hline Lower & 46 & 46 \\
\hline Middle & 29 & 29 \\
\hline Upper & 25 & 25 \\
\hline \multicolumn{3}{|c|}{ Booking status } \\
\hline Booked & 47 & 47 \\
\hline Unbooked & 53 & 53 \\
\hline \multicolumn{3}{|l|}{ Weight } \\
\hline$<45$ & 12 & 12 \\
\hline $45-60$ & 52 & 52 \\
\hline$>60$ & 36 & 36 \\
\hline \multicolumn{3}{|l|}{ Height } \\
\hline$<155$ & 47 & 47 \\
\hline $155-170$ & 49 & 49 \\
\hline$>170$ & 4 & 4 \\
\hline \multicolumn{3}{|l|}{ BMI } \\
\hline $18.5-24.9$ & 73 & 73 \\
\hline $25-29.9$ & 14 & 14 \\
\hline$>30$ & 13 & 13 \\
\hline
\end{tabular}


Table-2: Obstetric profile of the women

\begin{tabular}{|l|l|l|}
\hline Obstetric profile & Number & Percentages \\
\hline Gravidity & 60 & 60 \\
\hline Primigravida & 40 & 40 \\
Mulltigravida & 63 & 63 \\
\hline Parity & 26 & 26 \\
\hline Nullipara & 11 & 11 \\
Primipara & 5 & 5 \\
Multipara & 4 & 4 \\
\hline Past h/o preterm delivery & 3 & 3 \\
\hline Past h/o abortion & 3 \\
\hline Past h/o cesarean delivery & 3 & 35 \\
\hline Gestational age (weeks) & 35 & 65 \\
\hline$<34$ & 65 \\
$\geq 34$ & 46 & 46 \\
\hline No of ANC visit before admission \\
\hline None & 31 & 31 \\
$1-3$ & 23 & 23 \\
$\geq 4$ & & \\
\hline Present Mode of delivery & 96 & 96 \\
\hline Vaginal delivery & 4 & 4 \\
Cesarean delivery &
\end{tabular}

Table-3: Neonatal Outcome

\begin{tabular}{|l|l|l|}
\hline Neonatal Outcome & Number & Percentage \\
\hline Mode of delivery & \multicolumn{2}{|l|}{} \\
\hline Vaginal Delivery & 96 & 4 \\
Cesarean Delivery & 4 & 41 \\
\hline Gender of the baby & 41 & 59 \\
\hline Male & 59 & \\
Female & \multicolumn{2}{|l|}{} \\
\hline Birth weight & 3 & 3 \\
\hline$<1.0$ & 25 & 25 \\
$1.0-1.5$ & 38 & 38 \\
$1.5-2.0$ & 34 & 34 \\
$>2.0$ & 42 \\
\hline APGAR score & 58 & 42 \\
\hline$<7$ & 46 \\
$>7$ & 54 & 46 \\
\hline NICU admission & 54 \\
\hline Yes & \\
No & 12 & 12 \\
\hline Perinatal Mortality & 88 \\
\hline Yes & \\
No &
\end{tabular}

Table-4: Reasons for NICU admission

\begin{tabular}{|l|l|l|}
\hline $\begin{array}{l}\text { Reasons for NICU } \\
\text { admission }\end{array}$ & Number & Percentage \\
\hline $\begin{array}{l}\text { Extreme } \\
\text { prematurity }\end{array}$ & 16 & 16 \\
\hline Birth asphyxia & 42 & 42 \\
\hline Jaundice & 11 & 11 \\
\hline Septicemia & 12 & 12 \\
\hline Convulsion & 5 & 5 \\
\hline Hypoglycemia & 7 & 7 \\
\hline RDS & 10 & 10 \\
\hline Hypothermia & 5 & 5 \\
\hline
\end{tabular}

\section{DISCUSSION}

Preterm birth remains the leading cause of morbidity and mortality worldwide occurring in $7-11 \%$ of all deliveries [12]. Preterm births are influenced by many factors like maternal risk factors, pregnancy related complications, social and environmental factors.

In our study majority of the women $(85 \%)$ were in the age group 20 to 35 years. Our results were consistent with results of various studies done in the past [13-16]. Extremes of maternal age play large role in preterm birth. In present study $9 \%$ of the women were below 20 years of age, and $6 \%$ above 35 years as shown in Table 1. Result of our study was comparable with that observed by Shetty MB et al. [15]. Mean age of the women in our study was $23.45 \pm 3.9$ years which was comparable to $23.7 \pm 5.5$ years observed by Goldenberg et al. [2]. In our study $47 \%$ women with preterm labour had height less than $155 \mathrm{~cm}$. Percentage of the women having height $<155 \mathrm{~cm}$ is much higher in our study than that observed by Smith GC et al. [13] and Alijahan et al. [17] in their study. Women who were living in urban areas during pregnancy have a slightly less chance to have preterm delivery. Our results were consistent with the results observed by Theresia B Temu et al. [18] but were in contrast with the results observed by $\mathrm{H} \mathrm{Xu}$ et al. [19]. They observed that the incidence of preterm birth in urban areas was about 1.5 times that of rural areas. This was explained by them as the shift to an urban lifestyle leads to increased work pressure, a delay of child-delivering age, and increased adolescent pregnancy (early marriage) risk, which are all factors associated with high rates of preterm births [20]. $43 \%$ women in our study were illiterate i.e. had no formal education. Our results were consistent with the results observed by Wagura et al. [21] in their study. We observed that women with low socioeconomic status had more preterm deliveries. Our observation was consistent with study conducted by Purvi K Patel et al. [22] where low socio-economic status was found to be a significant risk factor. This might be attributed to the fact that low income women normally suffer from nutritional deficiency, insufficient health care, low education, drug abuse, cigarettes and alcohol consumption, domestic violence, and stressful life, all of them may cause preterm delivery [23].

In our study $73 \%$ women had normal BMI and $13 \%$ women had BMI more than $30 \mathrm{Kg} / \mathrm{m}^{2}$. In the study done by Alijahan et al. [17], 50.5\% women had normal BMI and $15.7 \%$ women had BMI more than $30 \mathrm{Kg} / \mathrm{m}^{2}$. Similarly Leal CM et al. [16] in their study observed that $64 \%$ women had normal BMI, $20.5 \%$ had BMI between 25 to $29.9 \mathrm{Kg} / \mathrm{m}^{2}$ and $6.7 \%$ had $\mathrm{BMI}>29.9$ $\mathrm{Km} / \mathrm{m}^{2}$ 
We observed in our study that preterm birth was higher in primigravida than multigravida women (60\% in primigravida $\mathrm{v} / \mathrm{s} 40 \%$ in multigravida). Our results were comparable with the observation made by Ahankari A et al. [24] who observed that preterm delivery was more in primigravida, but in contrast with that observed by Alijahan et al. [17], Sonia Arogya et al. [25] and Shetty MB et al. [15]. Sonia Arogya et al. [25] study shows that multiparous women have higher chances at preterm delivery. History of prior preterm birth and abortion in women with preterm pregnancy in our study was lower than that observed by various previous studies [16-18,21] Only 3\% women had prior cesarean delivery which was much lower than that observed by Leal CM et al. [16] and Alijahan et al. [17]. In our study $77 \%$ women with preterm labour had no or inadequate ANC visit before admission to the hospital. Percentage of the women with no or inadequate $\mathrm{ANC}$ visit in our study was much higher than that reported by Leal M C et al. [16].

Period of gestation is the most important determinant of postnatal outcome. Lesser the gestational age, worse would be the outcome [26]. In our study $65 \%$ women had gestational age of $\geq 34$ and $35 \%$ had gestational age $<34$ weeks and this is consistent with the observation made by other studies done in the past $[16,19,21,22]$. Singh U et al. [27] in their study reported that the maximum number of women $(48.5 \%)$ was in gestational age grouping of 3436 weeks. This could be due to the fact that with increasing gestational age there is more uterine distention which might stimulate the labour process. Mean Gestational age in our study was $33.8 \pm 2.1$ weeks which was comparable with mean gestational age observed by Akhter et al. [28] and more than mean gestational age of $30 \pm 1.7$ weeks observed by Dannapanenin et al. [29] in their study.

In our study $41 \%$ neonates were male and $59 \%$ were female, this mimics with the study done by Dannapanenin et al. [29] where $48 \%$ babies were male but in contrast to the previous studies done by various authors where majority of the neonates were female[19,26,30-31].

Perinatal morbidity and mortality is quite dependent on weight of the neonate at birth. In our study $72 \%$ neonates were > than $1.5 \mathrm{~kg}$ and $28 \%$ were < than $1.5 \mathrm{~kg}$, this is consistent with previous studies done by various authors [26, 30]. Mean birth weight of the babies in our study was $1.7 \pm 0.4 \mathrm{Kg}$ which was less than mean weight observed by Akhter et al. [28] in their studies but more than that observed by Dannapaneni $n$ et al. [29] in their study.

The optimal mode of delivery for preterm babies is controversial. In our study $96 \%$ women delivered vaginally and only $4 \%$ women delivered by cesarean section. In practice however the rate of elective caesarean deliveries in preterm babies has markedly increased over the last decade but it has been observed in various studies that caesarean delivery did not enhance neonatal survival of preterm infants nor did it decrease the morbidity in these infants [26,32] Rate of cesarean section for preterm babies varied from $13.9 \%$ to as high as $61 \%$ as observed by various authors in their studies[17,18,21,26,33]. In our study $42 \%$ babies had APGAR score $<7$ at 5 minute and $58 \%$ babies had APGAR 7 or more. The mean APGAR score at $5 \mathrm{~min}$ in our study was $7.02 \pm 1.03$ which was higher than that observed by Akhter et al. [28] in their study.

All over the world perinatal morbidity in preterm babies are observed frequently in developed as well as developing countries and preterm infants are more likely to be admitted to the Neonatal Intensive Care Unit as compared to term infants[34]. In our study $46 \%$ babies require neonatal admission which was lower than observed bu Akhtar et al. [28]. This difference could be because of difference in study design, local pediatric practice and relatively small sample size of our study. In our study various perinatal morbidities observed were birth asphyxia, extreme prematurity, neonatal jaundice, septicemia, convulsion, respiratory distress syndrome, neonatal hypoglycemia and hypothermia. Birth asphyxia was the commonest morbidity, $42 \%$ neonates had birth asphyxia. Extreme prematurity was the second commonest morbidity observed in this study (16\%).12\% neonates developed septicemia. Akhtar et al. in [28] their study also observed that most common indication for NICU admission was RDS, Sepsis and Low birth weight. Nargis Iqbal et al. [26] in their study observed birth asphyxia, RDS and feeding difficulties to be the common indications for NICU admission.

Neonatal hypoglycemia is a common morbidity in preterm neonates as the result of an insufficient metabolic response to the abrupt loss of maternal glucose supply after birth. In our study, hypoglycemia was diagnosed in $7 \%$ neonates. This is similar with other study [30]. Hypoglycemia may be symptomatic or asymptomatic. Prolonged hypoglycemia may result in neurological impairment and death [26].

Neonatal jaundice is a common morbidity seen in preterm infants. This is due to the immaturity of the hepatic enzymes. In our study, $11 \%$ neonates had hyperbilirubinemia. Phototherapy was required in these neonates. Previous studies also showed similar trends $[2,26,35]$. Neonatal septicemia occurred in $12 \%$ babies. Our results were consistent with other studies [26, 30, 35]. Preterm infants have high neonatal mortality rate than term infants. Perinatal mortality in our study was $12 \%$ which was comparable to that observed by Dannapaneni $\mathrm{n}$ et al. [29]. Perinatal mortality in our study was lower than that observed by Akhter et al.[28] Vidyadhar B. Bangal et al. [20] 
observed a very high perinatal mortality in their study $(42.4 \%)$.

\section{CONCLUSION}

Preterm labour is a significant cause of perinatal mortality (12\%) and morbidity (46\%). Perinatal survival can be improved by improving health services and NICU care. Providing proper education, pre-conceptional counseling regarding family planning, nutrition, hygiene and antenatal care will significantly reduce the incidence of preterm birth. The use of tocolysis, steroids prophylaxis, and antibiotics, along with timely referral to tertiary care, reduces the neonatal morbidity and mortality. Appropriate and innovative preventive intervention, customized individuals need may prevent preterm births and improve neonatal outcomes.

\section{REFERENCES}

1. Soon, B. T. (2012). The global action report on preterm birth. Geneva: World Health Organization.

2. Goldenberg, R. L., Culhane, J. F., Iams, J. D., \& Romero, R. (2008). Epidemiology and causes of preterm birth. The lancet, 371(9606), 75-84.

3. Heron, M., Sutton, P. D., Xu, J., Ventura, S. J., Strobino, D. M., \& Guyer, B. (2010). Annual summary of vital statistics: 2007. Pediatrics, 125(1), 4-15.

4. Goldenberg, R. L. (2002). The management of preterm labor. Obstetrics \& Gynecology, 100(5), 1020-1037.

5. Leitich, H.(2005). Controversies in diagnosis of preterm labor. Br J Obstet Gynaecol, March; 112 (suppl.): 61-3.

6. Carey, J. C., \& Gibbs, R. S. (2008). Preterm labor and post-term delivery. Danforth's Obstetrics \& Gynecology, 10th ed. Gibbs RS, Karlan BY, Haney $A F$, Nygaard IE, editors. Lippincott Williams \& Wilkins.

7. Honest, H., \& Khan, K. S. (2005). Preterm labour: prediction and treatment. Recent Advances in Obstetrics and Gynaecology, 23, 15-26.

8. Romero, R., Espinoza, J., Kusanovic, J. P., Gotsch, F., Hassan, S., Erez, O., ... \& Mazor, M. (2006). The preterm parturition syndrome. BJOG: $A n$ International Journal of Obstetrics \& Gynaecology, 113, 17-42.

9. Gotsch, F., Gotsch, F., Romero, R., Erez, O., Vaisbuch, E., Kusanovic, J. P., ... \& Yeo, L. (2009). The preterm parturition syndrome and its implications for understanding the biology, risk assessment, diagnosis, treatment and prevention of preterm birth. The Journal of Maternal-Fetal \& Neonatal Medicine, 22(sup2), 5-23.

10. Savitz, D. A., Kaufman, J. S., Dole, N., Siega-Riz, A. M., Thorp, J. M., \& Kaczor, D. T. (2004). Poverty, education, race, and pregnancy outcome. Ethnicity \& disease, 14(3), 322-329.
11. Wen, S. W., Smith, G., Yang, Q., \& Walker, M. (2004, December). Epidemiology of preterm birth and neonatal outcome. In Seminars in Fetal and Neonatal Medicine (Vol. 9, No. 6, pp. 429-435). WB Saunders.

12. Beck, S., Wojdyla, D., Say, L., Betran, A. P., Merialdi, M., Requejo, J. H., ... \& Van Look, P. F. (2010). The worldwide incidence of preterm birth: a systematic review of maternal mortality and morbidity. Bulletin of the World Health Organization, 88, 31-38.

13. Smith, G. C., Pell, J. P., \& Dobbie, R. (2003). Interpregnancy interval and risk of preterm birth and neonatal death: retrospective cohort study. Bmj, 327(7410), 313.

14. Al-Dabbagh, S. A., \& Al-Taee, W. Y. (2006). Risk factors for pre-term birth in Iraq: a case-control study. BMC pregnancy and childbirth, 6(1), 13.

15. Shetty, M. B., Krupa, B., Malyala, M., Swarup, A., Pathadan, D. S., \& Pocha, S. (2017). Preterm birth: associated risk factors and outcome in tertiary care center. Int $J$ Reprod Contracept Obstetr Gynecol, 6(8), 3271-3274.

16. do Carmo Leal, M., Esteves-Pereira, A. P., Nakamura-Pereira, M., Torres, J. A., Theme-Filha, M., Domingues, R. M. S. M., ... \& Gama, S. G. (2016). Prevalence and risk factors related to preterm birth in Brazil. Reproductive health, 13(3), 127.

17. Alijahan, R., Hazrati, S., Mirzarahimi, M., Pourfarzi, F., \& Hadi, P. A. (2014). Prevalence and risk factors associated with preterm birth in Ardabil, Iran. Iranian journal of reproductive medicine, 12(1), 47.

18. Temu, T. B., Masenga, G., Obure, J., Mosha, D., \& Mahande, M. J. (2016). Maternal and obstetric risk factors associated with preterm delivery at a referral hospital in northern-eastern Tanzania. Asian Pacific Journal of Reproduction, 5(5), 365-370.

19. Xu, H., Dai, Q., Xu, Y., Gong, Z., Dai, G., Ding, M., ... \& Hu, F. B. (2015). Time trends and risk factor associated with premature birth and infants deaths due to prematurity in Hubei Province, China from 2001 to 2012. BMC pregnancy and childbirth, 15(1), 329.

20. McDonald, S. D., McKinney, B., Foster, G., Taylor, V., Lutsiv, O., \& Pullenayegum, E. (2015). The combined effects of maternal depression and excess weight on neonatal outcomes. International journal of obesity, 39(7), 1033-1040.

21. Wagura, P., Wasunna, A., Laving, A., \& Wamalwa, D. (2018). Prevalence and factors associated with preterm birth at kenyatta national hospital. BMC pregnancy and childbirth, 18(1), 107.

22. Patel, P. K., Pitre, D. S., \& Bhooker, S. P. (2015). Predictive value of various risk factors for preterm labor. Community Med, 6(1), 121-5. 
23. Murphy, D. J. (2007). Epidemiology and environmental factors in preterm labour. Best Practice \& Research Clinical Obstetrics \& Gynaecology, 21(5), 773-789.

24. Ahankari, A., Bapat, S., Myles, P., Fogarty, A., \& Tata, L. (2017). Factors associated with preterm delivery and low birth weight: a study from rural Maharashtra, India. F1000Research, 6.

25. Kollmann, M., Gaulhofer, J., Lang, U., \& Klaritsch, P. (2016). Placenta praevia: incidence, risk factors and outcome. The Journal of MaternalFetal \& Neonatal Medicine, 29(9), 1395-1398.

26. Iqbal, N., Azhar, I. A., Ahmad, I., \& Tayyab, M. (2013). A study of neonatal outcome associated with preterm birth in a tertiary care hospital. Annals of King Edward Medical University, 19(3), 231-231.

27. Uma, S., Nisha, S., \& Shikha, S. (2007). A prospective analysis of etiology and outcome of preterm labor. Journal of Obstetrics and Gynecology of India, 57(1), 48-52.

28. Akhter, G., Rizvi, S. M., Hussain, S. I., Ali, F., \& Ali, A. (2015). Evaluation of perinatal outcome in preterm labour. International Journal of Current Research and Review, 7(21), 66.

29. Dannapaneni, N., Oleti, T., Surapaneni, T., Sharma, D., \& Murki, S. (2017). Immediate neonatal outcomes of preterm infants born to mothers with preterm pre-labour rupture of membranes. The Indian journal of medical research, 146(4), 476.
30. Abu-Salah, O. (2011). Unfavourable outcomes associated with late preterm birth: observations from Jordan. JPMA-Journal of the Pakistan Medical Association, 61(8), 769.

31. Irshad, M., Ahmad, A., Ahmed, K. F., Hayat, M., Kareem, R., Hussain, M., ... \& Khan, B. (2012). Risk factors for preterm births in a tertiary care hospital, lady reading hospital, peshawar. JPMI: Journal of Postgraduate Medical Institute, 26(2).

32. Sonkusare, S., Rai, L., \& Naik, P. (2009). Preterm birth: mode of delivery and neonatal outcome. Medical Journal of Malaysia, 64(4), 303306.

33. Silveira, M. F., Victora, C. G., Barros, A. J., Santos, I. S., Matijasevich, A., \& Barros, F. C. (2010). Determinants of preterm birth: Pelotas, Rio Grande do Sul state, Brazil, 2004 birth cohort. Cadernos de saude publica, 26, 185-194.

34. Larroque, B., Ancel, P. Y., Marret, S., Marchand, L., André, M., Arnaud, C., ... \& Burguet, A. (2008). Neurodevelopmental disabilities and special care of 5-year-old children born before 33 weeks of gestation (the EPIPAGE study): a longitudinal cohort study. The Lancet, 371(9615), 813-820.

35. Rehana, T. (2006). Preterm delivery: a major predictor of perinatal morbidity and mortality. Journal of Postgraduate Medical Institute (Peshawar-Pakistan), 20(3).

36. Bangal, V. B. (2012). A study of risk factors and perinatal outcome in preterm labour at tertiary care hospital. Hypertension, 10, 14-08. 